\title{
Pemetaan Jasa Ekosistem Mangrove pada Wilayah Rehabilitasi di Pesisir Sayung, Kabupaten Demak
}

\section{(Mapping of Mangrove Ecosystem Services in Rehabilitation Areas of Sayung Coastal Zone, Demak District)}

\author{
Setyo Handayani ${ }^{1,2 \star}$, Luky Adrianto ${ }^{3,5}$, Dietriech Geoffrey Bengen ${ }^{4}$, I Wayan Nurjaya ${ }^{4,5}$, Yusli \\ Wardiatno $0^{3,5,6}$
}

(Diterima Februari 2020/Disetujui Juli 2020)

\begin{abstract}
ABSTRAK
Ekosistem mangrove di pesisir Kecamatan Sayung memberikan jasa ekosistem yang sangat besar kepada masyarakat. Terlebih wilayah ini selama beberapa dekade terakhir mengalami erosi pantai yang sangat memprihatinkan. Informasi mengenai jasa ekosistem mangrove di wilayah ini masih sangat terbatas. Penelitian ini bertujuan untuk melakukan pemetaan keseimbangan jasa ekosistem mangrove di pesisir Kecamatan Sayung, Kabupaten Demak. Pengambilan data dilakukan di tiga desa pesisir, yaitu Desa Bedono, Timbulsloko, dan Surodadi. Teknik pengambilan data dilakukan dengan cara wawancara mendalam, penyebaran kuesioner, dan observasi lapang. Data dianalisis dengan pendekatan model Burkhard, yaitu matriks jasa ekosistem yang terdiri atas matriks kapasitas, permintaan, dan ketersediaan. Hasil analisis menunjukkan bahwa pada semua komponen jasa penyedia terjadi surplus ketersediaan. Pada jasa pengaturan, surplus rendah terdapat pada komponen penyerap karbon dan pengatur kualitas air, sedangkan defisit rendah ditemukan pada komponen penahan arus dan gelombang, penahan angin kencang dan badai, serta pencegah intrusi air laut. Pada jasa budaya, komponen tempat berteduh dan rekreasi mengalami surplus ketersediaan. Rehabilitasi mangrove perlu terus dilakukan untuk meningkatkan tutupan dan luasan mangrove, mengingat ketersediaan jasa pengaturan pada komponen yang terkait dengan perlindungan pantai dan penanggulangan erosi pantai berada pada neraca seimbang yang cenderung defisit.
\end{abstract}

Kata kunci: ekosistem mangrove, jasa ekosistem, model Burkhard, pesisir Sayung

\section{ABSTRACT}

The mangrove ecosystems on the coast of Sayung Sub-District provide huge benefits to the community. However, this region experienced a very severe coastal erosion during the last few decades. Also, information about mangrove ecosystem services is still very limited in this region. The purpose of this study, therefore, was to map the balance of mangrove ecosystem services on the coast of Sayung Sub-District, Demak District. Data were collected from three coastal villages, namely Bedono, Timbulsloko, and Surodadi, through in-depth interviews, questionnaires, and field observations. The data analysis was carried out using the Burkhard model approach, which involved an ecosystem service matrix, made up of a matrix of capacity, demand, and availability. The results showed that in all components of provisioning service, there was a surplus of availability. In regulating services, there were low surpluses in the components of carbon sequestration and water bioremediation services, while low deficits were found in the service components of reduce wave and current damage, and protecting from sea water intrusion. Then, in cultural services, the two components, shelter for rest area and recreation, experienced a surplus of availability. Mangrove rehabilitation needs to be continued to increase mangrove cover, given the availability of regulating services on components related to erosion prevention in the balace sheet tends to be deficit.

Keywords: Burkhard Model, ecosystem services, mangrove ecosystem, Sayung coastal

${ }^{1}$ Dinas Kelautan dan Perikanan Provinsi Jawa Tengah. Jl. Imam Bonjol No. 134 Semarang 50131

2 Sekolah Pascasarjana, Fakultas Perikanan dan IImu Kelautan, Institut Pertanian Bogor, Kampus IPB Darmaga, Bogor 16680

${ }^{3}$ Departemen Manajemen Sumberdaya Perairan, Fakultas Perikanan dan Ilmu Kelautan, Institut Pertanian Bogor, Kampus IPB Darmaga, Bogor 16680

4 Departemen Ilmu dan Teknologi Kelautan, Fakultas Perikanan dan Ilmu Kelautan, Institut Pertanian Bogor, Kampus IPB Darmaga, Bogor 16680

${ }^{5}$ Pusat Kajian Sumberdaya Pesisir dan Lautan, Institut Pertanian BiogorKampus IPB Baranangsiang, Bogor 16127

${ }^{6}$ Pusat Penelitian Lingkungan Hidup, Lembaga Penelitian dan Pengabdian Kepada Masyarakat, Institut Pertanian Bogor, Kampus IPB Darmaga, Bogor 16680

* Penulis Korespondensi: Email: yanisetyo@gmail.com

\section{PENDAHULUAN}

Jasa ekosistem adalah manfaat yang diperoleh manusia, baik secara langsung maupun tidak langsung, dari suatu ekosistem (Costanza et al. 1997; MEA 2005; Burkhard et al. 2010; Hayha \& Franzese 2014). Jasa ekosistem pesisir didefinisikan sebagai manfaat yang diperoleh manusia dari ekosistem yang ada di pesisir, di antaranya ekosistem mangrove, ekosistem lamun, dan ekosistem terumbu karang. Ketiga ekosistem tersebut memberikan jasa ekosistem pesisir berupa jasa pendukung, jasa pengaturan, jasa penyedia, dan jasa budaya (MEA 2005). 
Pendekatan jasa ekosistem digunakan sebagai instrumen yang menghubungkan antara fungsi ekosistem dengan kesejahteraan manusia (Sofian et al. 2019). Aktivitas manusia akan menyebabkan perubahan pada ekosistem yang di dalamnya terkandung keanekaragaman hayati dan kemudian akan berpengaruh pada kehidupan manusia itu sendiri, terutama dari aspek kesejahteraan (Coulthard et al. 2011). Faktor sosial, ekonomi, dan budaya juga ikut berperan dalam perubahan yang dapat terjadi, baik dalam skala lokal, regional, dan global (Lele et al. 2013).

Jasa ekosistem merupakan bagian penting dalam pengelolaan suatu ekosistem (Sofian et al. 2019). Analisis jasa ekosistem diperlukan sebagai dasar pengelolaan suatu ekosistem (Sjafrie 2016). Analisis jasa ekosistem dapat dilakukan dengan membuat matriks keseimbangan jasa ekosistem. Matriks keseimbangan jasa ekosistem dapat digunakan untuk mengetahui besaran supply dan demand pada jasa ekosistem karena jika permintaan lebih besar daripada kapasitas maka akan terjadi degradasi ekologis. Burkhard et al. (2012) telah melakukan analisis jasa ekosistem dengan menggunakan matriks hubungan antara jasa ekosistem dengan tutupan lahan dan dituangkan dalam bentuk spasial. Sjafrie et al. (2015) melakukan analisis jasa ekosistem lamun dengan menggunakan matriks keseimbangan antara jasa ekosistem dengan tipe habitat dan morfologi.

Fikriyani \& Mussadun (2014) dan Putri et al. (2014) melaporkan bahwa ekosistem mangrove di Kecamatan Sayung mengalami kerusakan pada awal tahun 1980an dikarenakan adanya konversi lahan mangrove menjadi tambak. Kerusakan mangrove yang merupakan pelindung alami ditambah dengan adanya kegiatan reklamasi dan bangunan pantai di wilayah yang berdekatan dengan pesisir Sayung menyebabkan erosi pantai (Asiyah et al. 2015; Ervita \& Marfai
2017). Berbagai upaya penanggulangan erosi pantai telah dilakukan pemerintah maupun swasta, di antaranya dengan program rehabilitasi mangrove. Upaya rehabilitasi mangrove berhasil meningkatkan tutupan mangrove di pesisir Sayung. Handayani et al. (2020) melaporkan bahwa pada tahun 2009, mangrove hanya ditemukan di 4 desa pesisir Sayung dengan luasan total $37,34 \mathrm{Ha}$. Pada tahun 2019 mangrove terdistribusi pada 6 desa dengan total luasan 225,17 Ha. Peningkatan luasan mangrove di Kecamatan Sayung sejalan dengan hasil penelitian Fikriyani \& Mussadun (2014), Faturrohmah \& Marjuki (2017), dan Irsadi et al. (2019). Peningkatan luasan mangrove mengindikasikan suksesnya program rehabilitasi.

Analisis jasa ekosistem pada ekosistem mangrove perlu dilakukan untuk melihat keseimbangan jasa ekosistem antara pemanfaat (manusia) dengan yang dimanfaatkan (sumber daya mangrove). Penelitian ini bertujuan untuk melakukan pemetaan keseimbangan jasa ekosistem mangrove pada daerah rehabilitasi akibat erosi pantai. Hasil dari penelitian ini diharapkan dapat digunakan sebagai dasar pengelolaan ekosistem mangrove ke depan, mengingat ekosistem mangrove memiliki peran yang sangat penting bagi pesisir Kecamatan Sayung, utamanya sebagai pelindung pantai.

\section{METODE PENELITIAN}

\section{Lokasi Studi}

Lokasi penelitian di pesisir Kecamatan Sayung, Kabupaten Demak terdiri atas tiga desa, yaitu Desa Bedono, Timbulsloko, dan Surodadi (Gambar 1). Pengambilan data lapang dilaksanakan selama 2 bulan, yaitu pada bulan Juli dan bulan Agustus 2019.

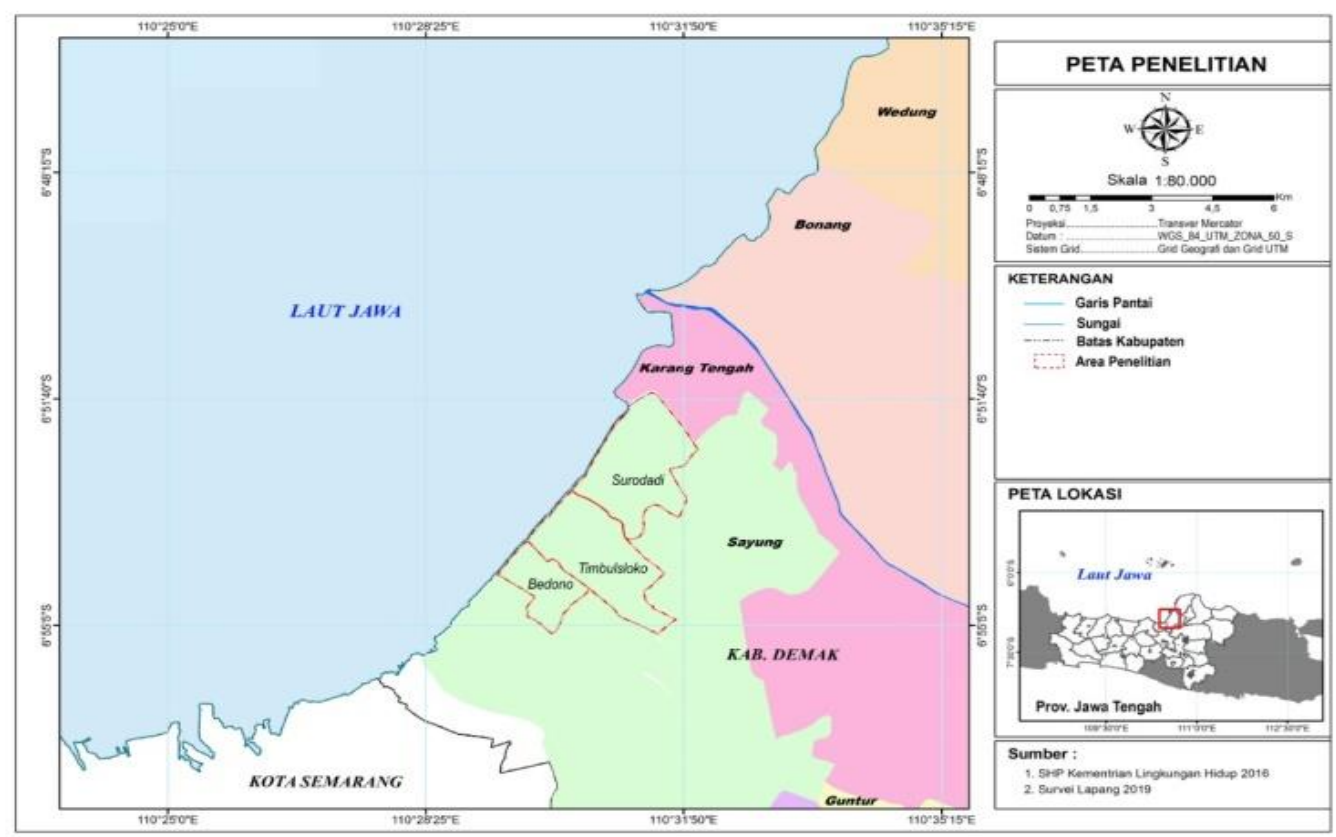

Gambar 1 Lokasi penelitian di pesisir Kecamatan Sayung, Kabupaten Demak. 
Objek penelitian ini adalah masyarakat pesisir yang berinteraksi dengan ekosistem mangrove.

\section{Pengumpulan Data}

Penentuan jasa ekosistem dan kapasitas jasa ekosistem mangrove yang terdapat di pesisir Kecamatan Sayung dilakukan dengan cara teknik wawancara mendalam (in-depth interview). Responden pada penelitian ini berasal dari akademisi/perguruan tinggi, Dinas Kelautan dan Perikanan Kabupaten Demak, Dinas Kelautan dan Perikanan Provinsi Jawa Tengah, tokoh masyarakat, dan Lembaga Swadaya Masyarakat (LSM) pemerhati lingkungan.

Penilaian permintaan jasa ekosistem dilakukan dengan cara pengisian kuesioner dan observasi lapang. Responden adalah masyarakat yang memanfaatkan dan tinggal di sekitar ekosistem mangrove, seperti nelayan dan petambak. Jumlah responden adalah sebanyak 38 orang yang ditampilkan dalam kerangka sampling responden pada Gambar 2. Jumlah ini sudah cukup memenuhi syarat minimum statistika sebagaimana Kerlinger \& Lee (2000) menyarankan sebanyak 30 sampel sebagai jumlah minimal sampel dalam penelitian kuantitatif. Sitorus (1998) juga menyatakan bahwa jumlah responden didasarkan pada syarat kecukupan informasi menurut justifikasi peneliti serta efisiensi di mana data yang diperoleh mencukupi kebutuhan penelitian.

\section{Analisis Data}

\section{- Identifikasi jasa ekosistem mangrove}

Identifikasi jasa ekosistem mangrove bertujuan untuk mendapatkan pemetaan komponen jasa penyedia, jasa pengaturan, jasa budaya, dan jasa pendukung. Identifikasi jasa ekosistem dilakukan melalui studi literatur, hasil kuesioner, wawancara, serta observasi lapang. Pada kegiatan ini juga dilakukan identifikasi manfaat pada tiap bagian mangrove, yaitu substrat, kolom air, dan pohon (akar, batang, daun, dan buah).

\section{- Penilaian jasa ekosistem mangrove}

Penilaian jasa ekosistem mangrove dilakukan dengan mengadopsi matriks penilaian yang direkomendasikan oleh Burkhard et al. (2012) dan Sjafrie et al. (2015). Matriks penilaian terdiri atas tiga komponen, yaitu a) Matriks kapasitas (supply) jasa ekosistem mangrove, b) Matriks permintaan (demand) jasa ekosistem mangrove, dan c) Matriks ketersediaan (budget) jasa ekosistem mangrove.

Penilaian pada matriks kapasitas dimaksudkan untuk mengetahui potensi sumber daya mangrove yang dapat dimanfaatkan oleh manusia. Penilaian tersebut diperoleh dengan melakukan wawancara mendalam dengan beberapa ahli yang mengetahui ekosistem mangrove secara menyeluruh, studi literatur, pengamatan penulis, serta informasi yang diperoleh di lapangan. Matriks kapasitas menggambarkan supply yang ada dari manfaat mangrove pada tiap jenis pemanfaatan. Penilaian pada matriks kapasitas memiliki kisaran nilai $1-5$, yang menunjukkan tingkat kapasitas jasa ekosistem yang tersedia.

Penilaian matriks permintaan dimaksudkan untuk mengetahui jasa ekosistem mangrove yang telah dimanfaatkan dan dirasakan oleh masyarakat. Penilaian pada matriks permintaan dilakukan berdasarkan pada hasil kuesioner dari responden. Penilaian matriks permintaan mempunyai kisaran nilai antara $1-5$, yang menunjukkan tingkat pemanfaatan jasa ekosistem. Jawaban responden terhadap pertanyaan tentang pemanfaatan ekosistem mangrove menggunakan skala Likert, yaitu 1 (sangat rendah), 2 (rendah), 3 (sedang), 4 (tinggi), dan 5 (sangat tinggi). Jawaban tersebut kemudian dikelompokkan dan dikategorikan dalam 5 kelas dengan interval setiap kelas diukur dengan kriteria seperti yang tercantum dalam Tabel 1.

Untuk melihat keseimbangan jasa ekosistem, dalam artian hubungan antara pemanfaat (manusia) dengan yang dimanfaatkan (sumber daya alam) dipresentasikan dalam matriks ketersediaan. Dalam matriks ketersediaan dapat terlihat jenis-jenis jasa ekosistem

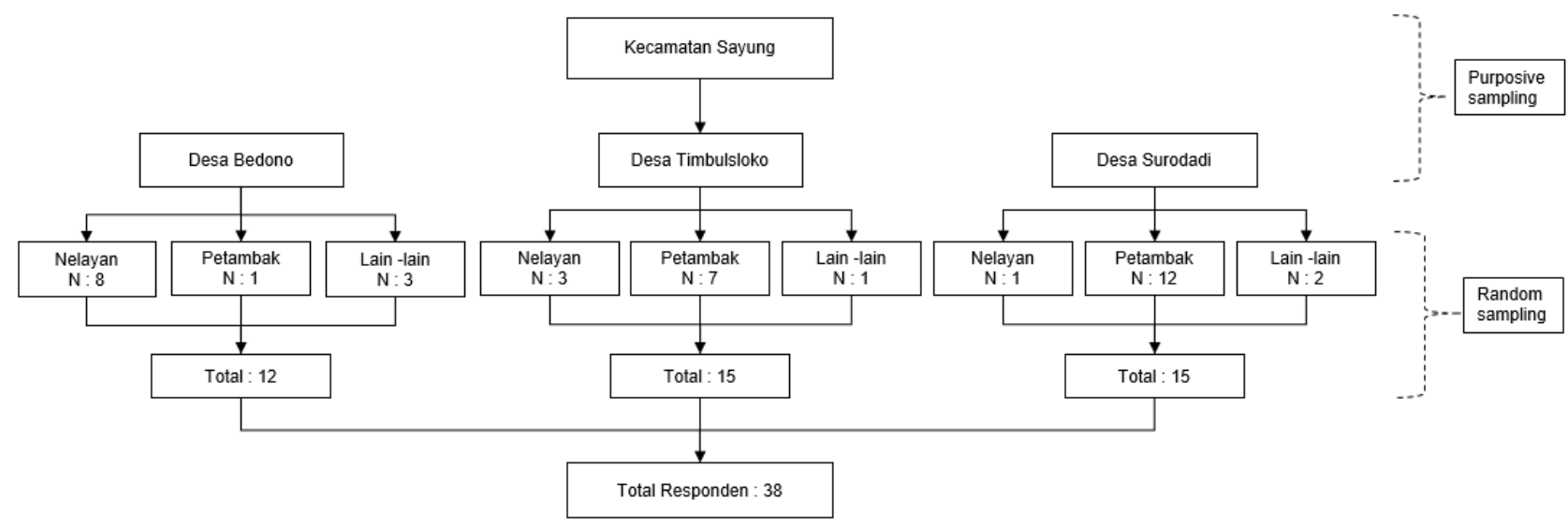

Gambar 2 Kerangka sampling responden. 
yang dimanfaatkan dan yang tidak dimanfaatkan. Penilaian matriks diperoleh dari hasil pengurangan antara matriks supply dengan matriks demand. Kisaran nilai matriks mulai dari -5 sampai 5 , yang menunjukkan tingkat ketersediaan (neraca) jasa ekosistem.

\section{HASIL DAN PEMBAHASAN}

\section{Identifikasi Jasa Ekosistem Mangrove}

Hasil identifikasi jasa ekosistem mangrove diketahui bahwa ada 21 jasa ekosistem mangrove yang terdapat di Desa Bedono, Timbulsloko, dan

Tabel 1 Kriteria penilaian matriks demand jasa ekosistem mangrove

\begin{tabular}{ccl}
\hline Selang kelas & Nilai & \multicolumn{1}{c}{ Kategori } \\
\hline $1,00-1,80$ & 1 & Sangat rendah \\
$1,81-2,60$ & 2 & Rendah \\
$2,61-3,40$ & 3 & Sedang \\
$3,41-4,20$ & 4 & Tinggi \\
$4,21-5,00$ & 5 & Sangat tinggi \\
\hline
\end{tabular}

Surodadi (Gambar 3). Jasa ekosistem tersebut dikelompokkan ke dalam jasa penyedia, jasa pengaturan, jasa budaya, dan jasa pendukung.

\section{Pemetaan Jasa Ekosistem}

Potensi sumber daya mangrove yang dimanfaatkan oleh masyarakat pada tiap bagiannya ditampilkan dalam matriks kapasitas jasa ekosistem mangrove (Tabel 2). Pemanfaatan pada masing-masing jasa ekosistem pada tiap bagian mangrove ditampilkan dalam matriks permintaan jasa ekosistem (Tabel 3). Pada matriks tersebut hanya dilakukan penilaian pada jasa penyedia, jasa pengaturan, dan jasa budaya. Penilaian terhadap jasa pendukung tidak dilakukan karena keterbatasan dalam mengkuantifikasi nilai jasa pendukung. Ketersediaan (budget) jasa ekosistem mangrove ditampilkan dalam matriks ketersediaan (Tabel 4).

\section{Pemetaan Jasa Ekosistem Mangrove \\ - Jasa pendukung}

Jasa pendukung banyak terkait dengan fungsi biologis ekosistem mangrove. Mangrove berfungsi

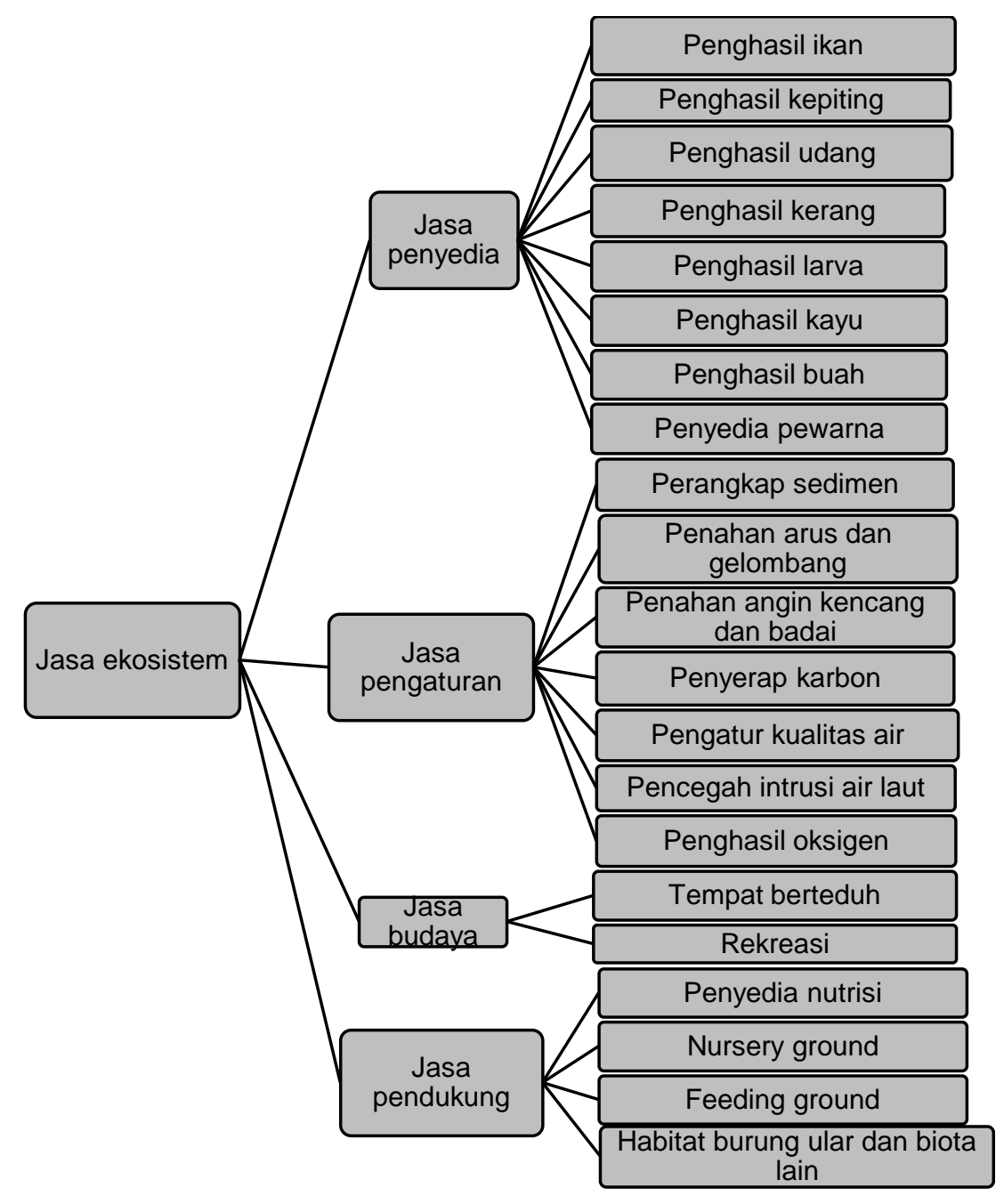

Gambar 3 Jasa Ekosistem Mangrove di Kecamatan Sayung. 
Tabel 2 Matriks kapasitas (supply) jasa ekosistem mangrove

\begin{tabular}{|c|c|c|c|c|c|}
\hline \multirow{2}{*}{ Tipe pemanfaatan } & \multirow{2}{*}{ Substrat } & \multirow{2}{*}{ Kolom air } & \multicolumn{3}{|c|}{ Mangrove } \\
\hline & & & Akar & Batang & Daun/buah \\
\hline \multicolumn{6}{|l|}{ Jasa penyedia } \\
\hline Penghasil ikan & & 5 & 2 & & \\
\hline Penghasil kepiting & 4 & 5 & 3 & 1 & \\
\hline Penghasil udang & 2 & 5 & 2 & & \\
\hline Penghasil kerang & 5 & 2 & 4 & 1 & \\
\hline Penghasil larva & 3 & 5 & 4 & & \\
\hline \multicolumn{6}{|l|}{ Penghasil kayu } \\
\hline Penghasil buah & & & & & 5 \\
\hline Penyedia pewarna & & & 2 & 5 & \\
\hline \multicolumn{6}{|l|}{ Jasa pengaturan } \\
\hline Perangkap sedimen & & & 5 & & \\
\hline Penahan arus dan gelombang & & & 5 & 4 & \\
\hline Penahan angin kencang dan badai & & & 3 & 5 & 5 \\
\hline Penyerap karbon & 3 & 3 & 4 & 4 & 5 \\
\hline Pengatur kualitas air & 4 & 4 & 5 & & \\
\hline Pencegah intrusi air laut & & & 4 & 3 & 3 \\
\hline Penghasil oksigen & & & & & 5 \\
\hline \multicolumn{6}{|l|}{ Jasa budaya } \\
\hline Tempat berteduh & & & 1 & 4 & 5 \\
\hline Rekreasi & 1 & 2 & 4 & 5 & 5 \\
\hline \multicolumn{6}{|l|}{ Jasa pendukung } \\
\hline Penyedia nutrisi & 3 & 5 & 2 & 2 & 4 \\
\hline Nursery ground & 4 & 5 & 2 & 2 & 3 \\
\hline Feeding ground & 4 & 5 & 2 & 2 & 4 \\
\hline Habitat burung, ular, dan biota lain & & 2 & 2 & 2 & 4 \\
\hline
\end{tabular}

Keterangan: $\quad 0=$ Tidak ada kapasitas, $1=$ Kapasitas sangat rendah, = Kapasitas sedang, $\quad 4$ = Kapasitas tinggi, dan $\quad 5=$ Kapasitas sangat tinggi.

Tabel 3 Matriks permintaan (demand) jasa ekosistem mangrove

\begin{tabular}{|c|c|c|c|c|c|}
\hline \multirow{2}{*}{ Tipe pemanfaatan } & \multirow{2}{*}{ Substrat } & \multirow{2}{*}{ Kolom air } & \multicolumn{3}{|c|}{ Mangrove } \\
\hline & & & Akar & Batang & Daun/buah \\
\hline \multicolumn{6}{|l|}{ Jasa Penyedia } \\
\hline Penghasil ikan & & 4 & 2 & & \\
\hline Penghasil kepiting & 3 & 2 & 2 & 1 & \\
\hline Penghasil udang & 3 & 3 & 3 & & \\
\hline Penghasil kerang & 4 & 2 & 3 & 1 & \\
\hline Penghasil larva & 3 & 3 & 3 & & \\
\hline Penghasil kayu bakar & & & & 1 & \\
\hline Penghasil buah & & & & & 2 \\
\hline Penyedia pewarna & & & 1 & 1 & \\
\hline \multicolumn{6}{|l|}{ Jasa Pengaturan } \\
\hline \multicolumn{6}{|l|}{ Perangkap sedimen } \\
\hline \multicolumn{6}{|l|}{ Penahan arus dan gelombang } \\
\hline \multicolumn{6}{|l|}{ Penahan angin kencang dan badai } \\
\hline Penyerap karbon & 2 & 2 & 3 & 3 & 4 \\
\hline Pengatur kualitas air & 3 & 3 & 4 & & \\
\hline Pencegah intrusi air laut & & & 4 & 4 & 3 \\
\hline \multicolumn{6}{|l|}{ Penghasil oksigen } \\
\hline \multicolumn{6}{|l|}{ Jasa Budaya } \\
\hline Tempat berteduh & & & 1 & 2 & 3 \\
\hline Rekreasi & 1 & 1 & 2 & 3 & 3 \\
\hline
\end{tabular}

sebagai habitat ikan dan biota lainnya (Sasekumar et al. 1992; Barbier 2003; Saenger et al. 2013), baik dalam seluruh maupun sebagian siklus hidupnya (Nagelkerken et al. 2008). Mangrove berfungsi sebagai tempat mencari makan (feeding ground), tempat memijah (spawning ground), daerah asuhan (nursery ground) (Kalor et al. 2019; Kusmana et al. 2005; Mukherjee et al. 2014; Allen et al. 2012), dan tempat berkembang biak (pilulating ground) (Kusmana et al. 2005). Hal tersebut sejalan dengan hasil matriks kapasitas (Tabel 2) pada komponen penyedia nutrisi, nursery ground, feeding ground menunjukkan nilai 
Tabel 4 Matriks budget pada jasa ekosistem mangrove

\begin{tabular}{|c|c|c|c|c|c|}
\hline \multirow{2}{*}{ Tipe pemanfaatan } & \multirow{2}{*}{ Substrat } & \multirow{2}{*}{ Kolom air } & \multicolumn{3}{|c|}{ Mangrove } \\
\hline & & & Akar & Batang & Daun/buah \\
\hline \multicolumn{6}{|l|}{ Jasa Penyedia } \\
\hline Penghasil ikan & & 1 & 2 & & \\
\hline Penghasil kepiting & 1 & 3 & $\overline{1}$ & 0 & \\
\hline Penghasil udang & 0 & 2 & 0 & & \\
\hline Penghasil kerang & 1 & 0 & 1 & 0 & \\
\hline Penghasil larva & 0 & 2 & 1 & & \\
\hline Penghasil kayu & & & & 4 & \\
\hline Penghasil buah & & & & & 3 \\
\hline \multirow{2}{*}{\multicolumn{6}{|c|}{ Jasa Pengaturan }} \\
\hline & & & & & \\
\hline Perangkap sedimen & & & 0 & & \\
\hline Penahan arus dan gelombang & & & 0 & -1 & \\
\hline Penahan angin kencang dan badai & & & -1 & 0 & 0 \\
\hline Penyerap karbon & 1 & 1 & 1 & 1 & 1 \\
\hline Pengatur kualitas air & 1 & 1 & 1 & & \\
\hline Pencegah intrusi air laut & & & 0 & -1 & 0 \\
\hline $\begin{array}{l}\text { Penghasil oksigen } \\
\text { Jasa Budaya }\end{array}$ & & & & & 0 \\
\hline Tempat berteduh & & & 0 & 2 & 2 \\
\hline Rekreasi & 0 & 1 & 2 & 2 & 2 \\
\hline
\end{tabular}

sedang hingga sangat tinggi pada kolom air dan substrat.

Ekosistem mangrove merupakan daerah perlindungan bagi biota dari ancaman predator (Nagelkerken et al. 2008; Kalor et al. 2019). Kusmana et al. (2005) menambahkan bahwa mangrove merupakan tempat bersarang berbagai jenis satwa liar, terutama burung serta sumber plasma nutfah. Hasil matriks kapasitas pada komponen mangrove sebagai habitat burung, ular, dan biota lainnya menunjukkan nilai rendah pada akar dan batang mangrove, serta tinggi pada daun/buah mangrove (Tabel 2). Penilaian terhadap jasa pendukung pada matriks permintaan dan matriks budget tidak dilakukan karena keterbatasan dalam mengkuantifikasi nilai dari jasa pendukung.

\section{- Jasa penyedia}

Mangrove memberikan jasa penyedia, yaitu hasil perikanan. Mangrove mendukung peningkatan hasil tangkapan perikanan di wilayah pantai (Yulianto et al. 2016). Mangrove juga menjadi habitat bagi biota lainnya, seperti udang. Kelestarian sumber daya udang sangat bergantung pada kelestarian ekosistem mangrove (Lee 2004; Islam \& Haque 2004; Osmaneli et al. 2014). Ekosistem mangrove merupakan sumber makanan (nutrient retention) bagi ekosistem sekitarnya dan pendukung sistem eksternal sehingga produktivitas sistem meningkat (Saenger 2002, Kathiresan \& Bingham 2001). Mangrove berperan penting dalam mendukung perikanan komersil (Barbier 2000; Allen et al. 2012) dan perikanan demersal (Barbier 2000). Kerusakan mangrove akan berdampak pada penurunan produksi perikanan tangkap (Islam \& haque 2004) dan produksi perikanan di laut lepas (Barbier 2003).
Matriks budget pada Tabel 4 menunjukkan bahwa beberapa komponen penghasil ikan dan berbagai biota laut ekonomis menunjukkan neraca seimbang yang berarti nilai permintaan sama dengan nilai kapasitas. Beberapa komponen pada jasa penyedia menunjukkan surplus rendah hingga sedang yang berarti kapasitas melebihi permintaan dan keadaan tersebut menunjukkan bahwa pemanfaatan masih dapat dilakukan. Pemanfaatan perikanan di perairan Kecamatan Sayung dapat terus dikembangkan, namun perlu dikelola dengan baik dan bertanggung jawab untuk menjaga produktivitas sumber daya dan dapat terus berkelanjutan. Penggunaan alat tangkap yang tidak ramah dan merusak lingkungan, seperti sodo, arad, dan garuk perlu ditertibkan agar sumber daya tetap terjaga dan lestari. Sebagaimana dinyatakan dalam Charles (2001) bahwa pembangunan perikanan yang berkelanjutan harus mengakomodasi 4 aspek, di antaranya adalah keberlanjutan ekologi, sosioekonomi, komunitas, dan kelembagaan.

Komponen jasa penghasil kayu, baik sebagai bahan bangunan maupun kayu bakar, menunjukkan surplus yang tinggi. Dari hasil wawancara, masyarakat sudah jarang sekali memanfaatkan mangrove sebagai sumber kayu bakar karena sudah tergantikan dengan adanya gas elpiji. Sebagian pemilik tambak mempergunakan kayu mangrove untuk saluran air di tambaknya, namun penggunaannya sangat sedikit. Kesadaran masyarakat tentang pentingnya mangrove cukup tinggi sehingga mereka tidak menebang mangrove secara sembarangan. Larangan untuk menebang pohon mangrove juga diperkuat dengan adanya peraturan desa yang mengatur tentang pelestarian mangrove.

Surplus yang tinggi terlihat pada komponen penghasil buah dan pewarna alami. Komponen tersebut 
masih memiliki potensi dan peluang yang besar untuk dikembangkan. Pemerintah bekerja sama dengan lembaga lainnya telah beberapa kali mengadakan program pemberdayaan wanita pesisir, yaitu pembuatan makanan berbahan baku mangrove. Dengan adanya pelatihan tersebut masyarakat memiliki kemampuan untuk memanfaatkan mangrove agar mendapatkan nilai tambah. Sebagai contoh, pelatihan pemanfaatan buah mangrove menjadi tepung pengganti terigu dan olahannya sebagai alternatif pangan berbasis lokal. Mulyatun (2018) menyatakan bahwa buah lindur (Bruguiera gymnorrhiza Lamk) dan Brayo (Avicennia marina) memiliki kandungan karbohidrat dan protein yang lebih tinggi dari tepung terigu sehingga memiliki potensi untuk dikembangkan sebagai pengganti tepung terigu. Pembuatan makanan dari tepung mangrove dilakukan hanya pada saat ada pemesanan atau ada kegiatan atau event tertentu. Hal yang sama juga terjadi pada komponen penghasil pewarna alami. Pelatihan pembuatan batik dengan pewarna alami dari mangrove pernah dilakukan, namun masalah pemasaran menjadi kendala. Pemerintah perlu berperan dalam pendampingan pemasaran produk tersebut.

\section{- Jasa pengaturan}

Secara fisik, mangrove dapat menjaga daerah di belakangnya dari hempasan gelombang, angin, dan badai. Sistem perakaran yang khas pada mangrove dapat menghambat arus dan ombak sehingga menjaga garis pantai tetap stabil dan terhindar dari erosi pantai (Kusmana et al. 2005; Sugiarto \& Ekayanto 1996; Saenger 2002). Spalding et al. (2014) mencatat bahwa angin dan gelombang yang bertiup dari laut akan kehilangan energi sebesar 15-65\% ketika melewati akar dan cabang mangrove. Ekosistem mangrove juga berfungsi sebagai penyangga daratan dari intrusi air laut. Mangrove juga dapat menyaring polutan atau limbah sehingga dapat menjaga kualitas air laut. Mangrove dapat mengikat sedimen dan lumpur yang dibawa oleh sungai atau aliran air lainnya (Kusmana et al. 2005; Saenger 2002; Setyawan \& Winarno 2006). Mangrove berperan dalam stabilisasi iklim mikro (Saenger 2002). Ekosistem mangrove memiliki stok karbon yang terbesar dibandingkan ekosistem pesisir lainnya (Martuti et al. 2017). Ekosistem mangrove dapat menyimpan dan menyerap karbon dengan baik (Balino et al. 2000; Overbeek 2014; Siddique et al. 2012; Alemaheyu et al. 2014).

Pada jasa pengaturan terdapat beberapa komponen jasa ekosistem yang mengalami defisit rendah dan surplus rendah (Tabel 4). Komponen penyerap karbon dan pengatur kualitas air menunjukkan nilai surplus rendah, sedangkan komponen pencegah intrusi air laut menunjukkan defisit rendah. Pada komponen perlindungan pantai (penahan arus dan gelombang serta penahan angin kencang dan badai) dan penanggulangan erosi pantai (perangkap sedimen) terlihat neraca seimbang yang cenderung defisit rendah. Hal ini berarti bahwa kapasitas yang diberikan oleh ekosistem mangrove seluruhnya dimanfaatkan oleh masyarakat. Jasa pengaturan secara keseluruhan membutuhkan perhatian dan penanganan lebih lanjut. Pengelolaan ekosistem mangrove secara tepat perlu dilakukan agar ekosistem mangrove tetap berkelanjutan sehingga dapat memberikan jasa pengaturan bagi masyarakat setempat.

Wilayah pesisir Kecamatan Sayung selama beberapa dekade terakhir mengalami perubahan garis pantai (Marfai 2012; Ervita 2016; Ervita \& Marfai 2017; Irsadi et al. 2019). Wilayah pesisir Demak yang mengalami erosi pantai terbesar adalah Kecamatan Sayung, yaitu seluas 2.116,54 ha (KKP 2015). Erosi pantai yang terjadi di pesisir Sayung mencapai $5 \mathrm{~km}$ ke arah daratan (Marfai 2012). Erosi terparah terjadi di Desa Bedono dan Timbulsloko (Irsadi et al. 2019). Dampak erosi ini bagi masyarakat, di antaranya adalah kerusakan dan tergenangnya permukiman secara permanen sehingga pemerintah mengadakan program relokasi dan perpindahan penduduk Dukuh Senik, Desa Bedono karena tempat tinggal sudah terendam dengan air laut (Damaywanti 2013; Putri et al. 2014). Erosi yang terjadi di pesisir Sayung sudah sangat mengkhawatirkan dan mengancam kehidupan sosial ekonomi mayarakat. Dampak erosi pantai yang terjadi berupa dampak fisik, ekonomi, dan sosial. Dampak fisik terjadi pada mundurnya dan pergeseran garis pantai ke arah daratan yang mengakibatkan kerugian berupa kerusakan tambak maupun sawah yang berada di pinggir pantai. Kerusakan permukiman, bangunan, dan infrastruktur turut memperparah kondisi. Dampak sosial ekonomi terjadi pada kehilangan mata pencaharian dan perubahan tingkah laku dalam menghadapi erosi pantai. Dengan adanya rehabilitasi ekosistem mangrove yang dikombinasikan dengan hard structure lainnya maka pemerintah dan masyarakat berharap ekosistem mangrove mampu memberikan jasa pengaturannya sebagai pelindung terhadap terjangan arus gelombang dan angin kencang sehingga mampu mengurangi erosi pantai bahkan dapat menambah daratan dengan fungsi mangrove sebagai perangkap sedimen.

\section{- Jasa budaya}

Pada Tabel 4 disajikan bahwa surplus dijumpai pada jasa budaya komponen tempat berteduh dan tempat wisata. Animo masyarakat setempat untuk memanfaatkan ekosistem mangrove menjadi tujuan wisata dan rekreasi sangat besar dan hal ini didukung oleh permintaan ekowisata mangrove yang tinggi. Stakeholder bersama masyarakat terus berupaya menyiapkan dan mengembangkan ekosistem mangrove agar menjadi destinasi wisata unggulan. Pengembangan ekowisata mangrove di tiap desa pesisir hendaknya memiliki spesifikasi sehingga terdapat ciri khas dan daya tarik tersendiri. Ekowisata mangrove di Dukuh Tambaksari, Desa Bedono dapat dikembangkan sebagai wisata alam, wisata bahari, dan wisata budaya. Lokasi tersebut memiliki daya tarik ekosistem mangrove dan makam Syeh Mudzakir 
(penyebar Agama Islam) yang terletak di tengah laut. Konsep ekowisata mangrove bereligi sangat cocok diterapkan di lokasi tersebut (Prasetyo \& Suwandono 2014; Abidin et al. 2015). Ekowisata mangrove di Desa Surodadi dapat dikembangkan menjadi wisata edukasi perpaduan antara mangrove dengan tambak (sylvo fishery). Dari hasil wawancara diketahui bahwa tambak di Desa Surodadi masih memiliki produktivitas yang tinggi.

Dari hasil dan pembahasan di atas terlihat bahwa terdapat beberapa jasa ekosistem mangrove yang mengalami defisit. Rehabilitasi mangrove merupakan salah satu alternatif yang dapat terus dilakukan untuk memperbaiki dan meningkatkan jasa ekosistem mangrove, utamanya dalam jasa pengaturan pada komponen yang terkait dengan perlindungan pantai dan penanggulangan erosi. Penanggulangan erosi pantai berbasis ekosistem menawarkan restorasi ekosistem dan perlindungan pesisir sekaligus memberikan keuntungan kepada masyarakat berupa jasa ekosistem lainnya yang terkait dengan peningkatan kualitas dan kuantitas pendapatan. Menurut Campbell et al. (2009) bahwa pendekatan ekosistem akan meningkatkan ketahanan sosial dan sekaligus penurunan tingkat kerentanan (vulnerability) terhadap bencana. Colls et al. (2009) menambahkan keuntungan adaptasi berbasis jasa ekosistem yang meliputi konservasi biodiversitas, penyerap karbon, pengurangan risiko bencana, kelangsungan mata pencaharian, dan ketahanan pangan, serta manajemen sumber daya air yang berkelanjutan.

\section{KESIMPULAN}

Ekosistem mangrove di Kecamatan Sayung memiliki berbagai jasa ekosistem yang terdiri atas jasa pendukung, jasa penyedia, jasa pengaturan, dan jasa budaya. Surplus jasa penyedia dijumpai pada penghasil ikan, penghasil kepiting, penghasil udang, penghasil kerang, dan penghasil larva. Surplus yang tinggi terdapat pada penghasil buah dan penyedia pewarna alami. Pada jasa pengaturan, surplus rendah terjadi pada penyerap karbon dan pengatur kualitas air, sedangkan defisit rendah ditemukan pada penahan arus dan gelombang, penahan angin kencang dan badai, serta pencegah intrusi air laut. Pada jasa budaya, tempat berteduh dan rekreasi mengalami surplus ketersediaan.

Menyadari besarnya peranan ekosistem mangrove dalam menunjang kehidupan masyarakat di Kecamatan Sayung maka ekosistem mangrove perlu untuk dikelola secara berkelanjutan agar tetap terjaga dan dapat terus memberikan jasa ekosistem kepada masyarakat setempat. Rehabilitasi mangrove di pesisir Kecamatan Sayung perlu terus dilakukan untuk meningkatkan tutupan dan luasan ekosistem mangrove, mengingat ketersediaan jasa pengaturan pada komponen yang terkait dengan penanggulangan erosi pantai berada pada neraca seimbang yang cenderung defisit.

\section{UCAPAN TERIMA KASIH}

Penulis mengucapkan terima kasih kepada Pemerintah Provinsi Jawa Tengah selaku pemberi bantuan dana sehingga penelitian ini dapat terlaksana dengan baik.

\section{DAFTAR PUSTAKA}

Abidin MT, Suprapto S, Hartoko A. 2015. Analisa pengembangan ekowisata wilayah konservasi mangrove, Desa Bedono, Kecamatan Sayung, Kabupaten Demak. Diponegoro Journal of Maquares. 4(4): 80-89.

Alemaheyu F, Richard O, James MK, Wasonga $\mathrm{O}$. 2014. Assesment of mangroves covers change and biomass in Mide Creek, Kenya. Open Journal of Forestry. 4: 398-413. https://doi.org/10.4236/ ojf.2014.44045

Allen JH, Duvander J, Kubiszewski I, Ostrom E. 2012. Institutions for managing ecosystem services. Solutions. 2(6) : 44-49.

Asiyah S, Rindarjono MG, Muryani C. 2015. Analisis perubahan permukiman kumuh dan karakteristik permukiman kumuh akibat abrasi dan inundasi di pesisir Kecamatan Sayung, Kabupaten Demak Tahun 2003-2013. Jurnal GeoEco. 1(1): 83-100.

Balino BM, Michael JR, Fasham, Margaret CB. 2000. Biogeokimia Laut dan Perubahan Global. Stockholm (SE) : ICSU. (Diterjemahkan oleh Agus Setiawan). $32 \mathrm{hlm}$.

Barbier EB. 2000. Valuing the environment as input: review of aplications to mangrovefishery linkages. Ecological Economics. 35: 47-61. https:// doi.org/10.1016/S0921-8009(00)00167-1

Barbier EB. 2003. Habitat-fishery linkages and mangrove loss in Thailand. Contemporary Economic Policy. 21: 59-77. https://doi.org/ 10.1093/cep/21.1.59

Burkhard B, Petrosillo I, Costanza R. 2010. Ecosystem services-bridging ecology, economy and social sciences. Ecological Complexity. 7: 257-259. https://doi.org/10.1016/j.ecocom.2010.07.001

Burkhard B, Kroll F, Nedkov S, Muller F. 2012. Mapping ecosystem service supply, demand, and budgets. Ecological Indicators. 21: 17-29. https://doi.org/ 10.1016/j.ecolind.2011.06.019

Campbell A, Kapos V, Scharlemann JPW, Bubb P, Chenery A, Coad L, Rashid M. 2009. Review of 
literature on the links between biodiversity and climate change : impacts, adaptation and mitigation. In Secretariat of the convention on Biological Diversity, Montreal (US): Technical Series. No. 42. pp 124.

Charles AT. 2001. Sustainable Fishery Systems. London (EN): Blackwell Science Ltd. 370 p.

Colls A, Ash N, Ikkala N. 2009. Ecosystem-based adaptation: A natural response to climate change. Gland $(\mathrm{CH})$ : IUCN.

Costanza R, d' Arge R, de Groot R, Arberk S, Grasso M, Hannon B, Limburg K, Naeem S, O'Neill RV, Paruelo J. 1997. The value of the world's ecosystem services and natural capital. Nature. 387: 253-260. https://doi.org/10.1038/387253a0

Coulthard S, Johnson D, McGregor JA. 2011. Poverty, sustainability and human wellbeing: a social wellbeing approach to the global fisheries crisis. Global Environmental Change. 21(2): 453-463. https://doi.org/10.1016/j.gloenvcha.2011.01.003

Damaywanti K. 2013. Dampak abrasi pantai terhadap lingkungan sosial : studi kasus di Desa Bedono, Sayung Demak. Di dalam: Hadi PS, Purwanto, Sunoko HR, Purnaweni H, editor. Optimasi Pengelolaan Sumberdaya Alam dan Lingkungan dalam Mewujudkan Pembangunan Berkelanjutan; Seminar Nasional Pengelolaan Sumberdaya Alam dan Lingkungan. IImu Lingkungan, Universitas Diponegoro. Semarang, 10 September 2013.

Ervita K. 2016. Kajian perubahan garis pantai di Kabupaten Demak Tahun 1990-2015 ditinjau dari aspek morfodinamika. [Tesis]. Yogyakarta (ID): Universitas Gadjah Mada. https://doi.org/10.4236/ jep.2017.88059

Ervita K dan Marfai MA. 2017. Shoreline change analysis in Demak, Indonesia. Journal of Environmental Protection. 8: 940-955.

Handayani S, Bengen DG, Nurjaya IW, Adrianto L, Wardiatno Y. 2020. The sustainability status of mangrove ecosystem management in the rehabilitation area of Sayung coastal zone, Demak Regency, Central Java, Indonesia. AACL Bioflux. 13(2): 865-884.

Faturrohmah S, Marjuki B. 2017 Identifikasi dinamika spasial sumberdaya mangrove di wilayah pesisir Kabupaten Demak, Jawa Tengah. Majalah Geografi Indonesia. 31(1):

https://doi.org/10.22146/mgi.24234

Fikriyani M, Mussadun, 2014. Evaluasi program rehabilitasi mangrove di pesisir Desa Bedono, Kecamatan Sayung, Kabupaten Demak. Jurnal Perencanaan Wilayah dan Kota. 2(1): 381-390.

Hayha T, Franzese PP. 2014. Ecosystem services assessment : A review under an ecological- economic and systems perspective. Ecological Modelling. 289: 124-132. https://doi.org/10.1016/ j.ecolmodel.2014.07.002

Irsadi A, Anggoro S, Soeprobowati TR, Helmi M, Khair ASE. 2019. Shoreline and mangrove analysis along Semarang-Demak, Indonesia for sustainable environmental management. Jurnal Pendidikan IPA Indonesia. 8(1): 1-11. https://doi.org/10. 15294/jpii.v8i1.17892

Islam MS, Haque M. 2004. The mangrove-based coastal and nearshore fisheries of Bangladesh: ecology, exploitation and management. Reviews in Fish Biology and Fisheries. 14: 153-180. https:// doi.org/10.1007/s11160-004-3769-8

Kalor JD, Indrayani E, Akobiarek MNR. 2019. Fisheries resources of mangrove ecosystem in Demta Gulf, Jayapura, Papua, Indonesia. Aquaculture, Aquarium, Conservation and Legislation International Journal of the Bioflux Society. 12(1): 219-229.

Kathiresan K, Bingham BL. 2001. Biology of mangroves and mangrove ecosystems. Advances in Marine Biology. 40: 81-251. https://doi.org/ 10.1016/S0065-2881(01)40003-4

Kerlinger FN, Lee HB. 2000. Foundations of behavioral research. 4th Edition. Fort Worth (US): Harcourt College Publisher.

[KKP] Kementerian Kelautan dan Perikanan. 2015. Kajian lokasi prioritas rehabilitasi di wilayah pesisir Provinsi Jawa Tengah. DKP Jateng, Semarang (ID).

Kusmana C, Wilarso S, Iwan $\mathrm{H}$, Pamoengkas $\mathrm{P}$, Wibowo C, Tiryana T, Triswanto A, Yunasfi, Hamzah. 2005. Teknik rehabilitasi mangrove. Institut Pertanian Bogor. Bogor (ID).

Lee SY. 2004. Relationship between mangrove abundance and tropical prawn production: a reevaluation. Marine Biology. 145: 943-949. https:// doi.org/10.1007/s00227-004-1385-8

Lele S, Springate-Baginski O, Lakerveld R, Deb D, Dash P. 2013. Ecosystem services: origins, contributions, pitfalls, and alternatives. Conservation and Society. 11(4): 343-358. https://doi.org/ 10.4103/0972-4923.125752

Marfai MA. 2012. Preliminary assessment of coastal erosion and local community adaptation in Sayung coastal area, Central Java, Indonesia. Jurnal Quaestiones Geographicae. 31(3): 47-55.

Martuti NKT, Setyowati DL, Nugraha SB, Mutiatari DP. 2017. Carbon stock potency of mangrove scosystem at Tapak Sub-village, Semarang, Indonesia. Aquaculture, Aquarium, Conservation and Legislation - International Journal of the Bioflux Society. 10(6): 1524-1533. 
[MEA] Millenium Ecosystem Assessment. 2005. Ecosystems and Well-Human Being Synthesis. Washington (US): Island Press.

Mukherjee N, Sutherland WJ, Dicks L, Huge J, Koedam N, Dahdouh-Guebas F. 2014. Ecosystem services valuations of mangrove ecosystems to inform decision making and future valuation exercise. PLOS ONE. 9(9): 1-9. https://doi.org/ 10.1371/journal.pone.0107706

Mulyatun. 2018. Pemberdayaan masyarakat pesisir berbasis potensi lokal, alternatif ketahanan pangan berupat tepung mangrove. Dimas: Jurnal Pemikiran Agama untuk Pemberdayaan. 18(2): 211-238. https://doi.org/10.21580/dms.2018.182.3260

Nagelkerken I, Blaber SJ M, Bouillon S, Green P, Haywood M, Kirton LG, Meynecke JO, Pawlik J, Penrose HM, Sasekumar A, Somerfield PJ. 2008. The habitat function of mangroves for terrestrial and marine fauna: a review. Aquatic Botany. 89: 155-185. 2007.12.007

Osmaneli, Kusumastanto T, Ekayani M. 2014. Analisis ekonomi keterkaitan ekosistem mangrove dengan sumber daya Udang (studi kasus: Desa Pabean Udik, Kecamatan Indramayu). Journal of Agriculture, Resources, and Environmental Economics: 1(1): 61-70. https://doi.org/10.29244/ jaree.v1i1.11300

Overbeek W. 2014. Blue carbon and blue redd transforming coastal ecosystem, Into Merchandise. Misereor (Jerman) dan Swedish Society for Nature Conservation (SSNC).

Prasetyo E, Suwandono D. 2014. Konsep desa wisata hutan mangrove di Desa Bedono, Kecamatan Sayung, Kabupaten Demak. Jurnal Ruang. 2(4): 361-37.

Putri MP, Supriharyono, Muskananfola MR. 2014. Karakteristik hidro-oseanografi dan tingkat partisipasi masyarakat dalam menanggulangi kerusakan pantai di Desa Bedono, Kecamatan Sayung, Kabupaten Demak. Diponegoro Journal of Macquares. 3(4): 225-234.

Saenger P. 2002. Mangrove ecology, silviculture, and conservation. Dordrecht (NL): Kluwer Academic Publisher. https://doi.org/10.1007/978-94-0159962-7

Saenger P, Gartside D, Funge-Smith S. 2013. A review of mangrove and seagrass ecosystems and their linkage to fisheries and fisheries management. Report to Food and Agriculture Organization of the United Nations Regional Office for Asia and the Pacific Bangkok. Bangkok (TH).

Sasekumar A, Chong VC, Leh MU, D'Cruz R, 1992 Mangrove as a habitat for fish and prawns. Hydrobiologia. 247: 195-207. https://doi.org/ 10.1007/978-94-017-3288-8_21

Setyawan AD dan Kusumo Winarno. 2006. Permasalahan Konservasi Ekosistem Mangrove di Pesisir Kabupaten Rembang, Jawa Tengah. Biodiversitas 7(2): 159-163.

Siddique HRM, Hossain M, Chowdhury KRM. 2012. Allometric relationship for estimating above-ground biomass of Aegialitis rotundifolia roxb of sundarbans mangrove forest, in Bangladesh. Journal of Forestry Research. 23(1): 23-28. https:// doi.org/10.1007/s11676-012-0229-5

Sitorus MTF. 1998. Penelitian kualitatif: suatu perkenalan. Laboratorium Sosiologi, Antropologi dan Kependudukan. Institut Pertanian Bogor. Bogor (ID).

Sjafrie NDM. 2016. Jasa Ekosistem Pesisir. Oseana. 41(4): 25-40.

Sjafrie NDM, Adrianto L, Damar A, Boer M. 2015. Analisis keseimbangan jasa ekosistem lamun. Oseanologi dan Limnologi di Indonesia. 41(3): 291-304.

Sofian A, Kusmana C, Fauzi A, Rusdiana O. 2019. Ecosystem services-based mangrove management strategies in Indonesia: a review. Bioflux. 2(1): 151-166

Spalding, MD, Ruffo S, Lacambra C, Meliane I, Hale LZ, Shepard CC, Beck MW. 2014. The role of ecosystems in coastal protection : adapting to climate change and coastal hazards. Ocean. Coast. Manage. 90: 50-57. https://doi.org/10.1016/ j.ocecoaman.2013.09.007

Sugiarto W, Ekayanto. 1996. Penghijauan pantai. Jakarta (ID): Panebar Swadaya.

Yulianto G, Soewardi K, Adrianto Y, Machfud. 2016. The role of mangrove in support of coastal fisheries in Indramayu Regency, West Java, Indonesia. Aquaculture, Aquarium, Conservation and Legislation - International Journal of the Bioflux Society. 9 (5): 1020-1029 